\title{
Submission to Advances in Health Sciences Education
}

Short title: Medical students and relational identity

Title: Medical student stories of participation in patient care-related activities: the construction of relational identity

Authors:

1. Sally Warmington

2. Geoffrey McColl

Affiliations:

1. Honorary Fellow, Centre for Health Equity,

School of Population and Global Health,

Faculty of Medicine, Dentistry and Health Sciences,

The University of Melbourne, Victoria 3010, Australia.

2. Head, Melbourne Medical School,

Faculty of Medicine, Dentistry and Health Sciences,

The University of Melbourne, Victoria 3010, Australia.

$\underline{\text { Address for all correspondence: }}$

Sally Warmington

Phone: +61433763209

E-mail:sgwa@unimelb.edu.au

Fax: +61393729666 


\title{
Medical student stories of participation in patient care-related activities: the construction of relational identity
}

\author{
Abstract \\ Professional identity formation is acknowledged as one of the fundamental tasks of \\ contemporary medical education. Identity is a social phenomenon, constructed through \\ participation in everyday activities and an integral part of every learning interaction. In \\ this paper we report from an Australian ethnographic study into how medical students \\ and patients use narrative to construct their identities. The dialogic narrative analysis \\ employed focused on the production of meaning through the use of language devices in \\ a given context, and the juxtaposition of multiple perspectives. Two stories told by \\ students about their participation in patient care-related activities reveal how identities \\ are constructed in this context through depictions of the relationships between medical \\ students, patients and clinical teachers. These students use the rhetorical functions of \\ stories to characterise doctors and patients in certain ways, and position themselves in \\ relation to them. They defend common practices that circumvent valid consent \\ processes, justified by the imperative to maximise students' participation in patient \\ care-related activities. In doing so, they identify patients as their adversaries, and \\ doctors as allies. Both students are influenced by others' expectations but one reveals \\ the active nature of identity work, describing subtle acts of resistance. \\ These stories illustrate how practices for securing students' access to patients can \\ influence students' emerging identities, with implications for their future disclosure \\ and consent practices. We argue that more collaborative ways of involving medical
}


students in patient care-related activities will be facilitated if students and clinical teachers develop insight into the relational nature of identity work.

\section{Key words}

Medical students, professional identity formation, clinical teaching, narrative, dialogue, ethnography, relational identity, patient care, professionalism

\section{Introduction}

Professional identity formation is now acknowledged as a fundamental part of the development of both medical students and doctors in the workforce (Cooke et al, 2010; Cruess et al, 2014; Korica \& Molloy, 2010; Wilson et al, 2013). There has been an expansion of identity research in the medical education literature in recent years, much of which has been based on theory and methods from the social sciences (Bleakley et al, 2011); (Goldie, 2012) (Cohen et al, 2009; DelVecchio Good, 2011; Dornan et al, 2015; Holmes et al, 2011; Monrouxe, 2009a). Although identity can be understood as an internal project of the self, identities are also social phenomena, constructed through participation in everyday activities (Monrouxe, 2009a). The study of professional identity construction contributes to our understanding of the social and relational dimensions of medical students' learning, including those which relate to their mental health and well-being (Goldie, 2012) (Monrouxe, 2010).

According to the socio-cultural theory of education known as 'situated learning', professional identities always emerge in particular 'communities of practice' - of which a hospital is one example (Wenger, 1998). As newcomers progress with 
experience from peripheral forms of participation towards full involvement, they learn about that community's customary values and practices, including how members are expected to treat one another (Lave \& Wenger, 1991). By this account, the construction of identities is an integral part of learning about how the work is done in a given social and cultural context.

Identity construction is an integral part of every learning interaction (Bleakley et al., 2011), and has been shown to be influenced by customary practices and power dynamics in particular contexts (Monrouxe et al, 2009; Rees et al, 2013; Rees \& Monrouxe, 2008). As ways of working evolve in contemporary health care settings, with greater expectations for patient participation and increased emphasis on working in teams, new forms of identity can be expected to emerge (Bleakley et al., 2011). There has been limited focus in previous research on the relational aspects of identity. To address this gap, we explore in this paper how student and doctor identities are constructed in relation to those of the patients, clinical teachers and supervisors with whom they interact. In order to do so, we present and analyse medical students' narratives of their participation in patient care-related activities in a hospital setting. In this paper, the terms narrative and story are used to refer to accounts that explore motivations, actions and consequences (Garro \& Mattingly, 2000). In addition to conveying information, it is important to note that stories have rhetorical functions and create relationships between narrators and audiences (Good \& Good, 2000).

Identity is a dynamic phenomenon, emerging whenever people interact with each other and influenced by the particular social, cultural and material contexts of those encounters (Bleakley et al., 2011; de Fina et al, 2006; Lemke, 2008). Although this 
paper focuses on the use of language to construct identity during interactive storytelling, we acknowledge that this process also takes place by non-verbal means, such as the wearing of particular types of clothing, the possession and use of artefacts and bodily posture, position and movement (Lemke, 2008).

The study of professional identity construction contributes to our understanding of the social and relational dimensions of medical students' learning (Goldie, 2012;

Monrouxe, 2009a) as well as their mental health and well-being. Sharing stories of experiences with patients is a fundamental part of the way medicine is practiced and taught (Good \& Good, 2000). When faced with a challenging clinical situation, doctors and students may attempt to make sense of their present situation by talking with colleagues about similar cases and how they might relate to the present situation. By engaging in these acts of storytelling, they not only convey their version of events, but also construct and perform their identities by characterising story characters and events in particular ways and metaphorically 'positioning' themselves in relation to others (Wortham, 2000). This process of 'interactional positioning' can be made visible by analysing how a narrator conveys an evaluation of the story characters' actions or motivations by using particular words and expressions (Monrouxe, 2009a). This type of narrative identity work is done during clinical encounters as well as when students and doctors talk about them - for example, in conversations with peers, or in de-briefing sessions or research interviews.

Such a dynamic concept of identity may seem counter-intuitive, since we are accustomed to thinking about it as a relatively fixed and stable phenomenon. One way to make sense of this apparent paradox is to consider identities as emerging over a 
range of 'time-scales.' They are more fluid as they are constructed in-the-moment, but become more enduring with the recurrence of contact with people, objects and situations that call us to relate to them in similar ways (Lemke, 2008). Over time, multiple interactions in a variety of contexts result, not in one single identity, but instead in constellations of identities (de Fina et al., 2006; Iedema \& Caldas-Coulthard, 2008) (Goldie, 2012). From this perspective, identities are likely to be especially open to change as students enter new learning environments.

The limited, supervised involvement of medical students in doctors' everyday work is an essential part of their education, so gaining access to patients willing to allow this participation is vital. Fortunately, many patients are motivated to help with students' learning, citing altruistic concern for them and their future patients, as well as selfinterested motives (Chretien et al, 2010; Fletcher et al, 2005; McLachlan et al, 2012; Rice, 2008). However, involvement of students in patient care carries some risk of additional physical or emotional discomfort (Lauckner et al, 2012; McLachlan et al, 2012). Sound ethical practice requires that patients are informed about their proposed involvement in advance of deciding whether to give their consent, including the fact that they have the option to decline without any impact on their treatment (Chretien et al., 2010; Fletcher et al, 2007; Nair et al, 1997; Romano, 1941). However, medical students frequently witness and participate in patient care-related activities in circumstances where valid consent has not been obtained (Rees \& Monrouxe, 2011) (Coldicott et al, 2003). When fully informed consent to their participation is not obtained, this contributes to the tendency for patients to be restricted to passive roles in their interactions with students and clinical teachers, with limited opportunities for active collaboration. 
In this paper we report selected results from an ethnographic study undertaken in an Australian teaching hospital that explored medical students' and patients' use of narrative to construct identities. We focus here on students' stories about how they obtain opportunities to participate in patient care-related activities. Through the analysis of this narrative data, we address two inter-related questions: firstly, how are identities constructed in this context? Secondly, how are students' emerging identities shaped by their narrative characterisations of the relationships between themselves, patients and clinical teachers?

By building our understanding of identity as a dynamic and relational phenomenon, this research has the potential to enhance medical teachers' support for students' identity work and minimise the distress related to its inherent conflicts. Our focus on the ways medical students gain access to patients during care-related activities provides an opportunity for reflection on customary practices in relation to consent in this context. It also enables us to consider how to facilitate more collaborative ways of involving patients in students' learning.

\section{Methods}

\section{Research Design and Methodology}

Ethnography has a long history of application in medical education research (Becker et al, 1961; Lief \& Fox, 1963; Reeves et al, 2013; Sinclair, 1997), and is ideally suited to generating insights into complex social and cultural phenomena, exposing taken-forgranted practices, and offering "critiques of dominant systems and understandings" 
(Murchison, 2010, p. 5). Ethnographic research involves the immersion of the researcher in a cultural context for an extended period of time (Murchison, 2010). The collection of multiple forms of data from a variety of sources allows the research to generate a deeper and more comprehensive understanding of the phenomenon being studied (Reeves et al., 2013). Knowledge continues to emerge throughout the process of writing various ethnographic texts (Murchison, 2010; Reeves et al., 2013).

The design of the project was also guided by the principles of dialogism, as developed by Bakhtin and his circle of scholars (Gardiner \& Bell, 1998), who argued that human being or existence is an event, one that always takes place in relation to others, involving a creative struggle (Holquist, 2002). A dialogic approach is characterised by several key features. Firstly, attention is focused on how meaning emerges through the particular uses of language in interactions, including the forms of narrative, metaphor and rhetoric (Bleakley et al., 2011; Loftus, 2012). Secondly, the social and cultural contexts within which people interact are acknowledged as being critically important (Gubrium \& Holstein, 2009). Finally, a dialogic approach entails the identification and articulation of multiple distinct perspectives (Denzin, 1997). This can be considered as a way of placing many 'voices' from the data in dialogue with each other within 'multi-vocal' texts. The juxtaposition of different perspectives results in the emergence of new insights (de Fina et al., 2006). In contrast, interactions in which a single voice or perspective dominates or merges with others can be characterised as monologic (Frank, 2004b). 


\section{Reflexivity and ethical considerations}

In contemporary ethnographic research, it is essential for the researcher to engage in a process of reflexivity, meaning that his or her identity and position in relation to the context and participants is a matter for explicit reflection, and needs to be taken into account in the interpretation of the findings (Murchison, 2010; Reeves et al., 2013). The first author of this paper (from now on referred to as the researcher) is a practising physician with over thirty years' clinical experience. Her identity as a doctor was disclosed freely to participants and others in the field, but she emphasised the fact that the purpose of her presence was to carry out research. There are a number of challenges to be faced by a physician-ethnographer in a hospital context, including maintaining the boundaries between the role of researcher and those of clinician or teacher, and recognising the power dynamics in interactions with patients, medical students and clinical teachers. There were parallels between students' position in relation to seeking patients to practice their history and examination techniques, and the position of the student researcher in relation to potential or enrolled research participants. Medical students and student-researcher had to negotiate each and every interaction, experience apprehension about potential rejection and uncertainty as to how to perform their new roles competently. Reflecting on these experiences throughout the project, during the researcher's interactions with research participants and at another level, in her conversations with supervisors and peers allowed her to construct a new aspect of her identity - that of a physician-ethnographer. 
Reflection on these matters was accomplished through journal writing and discussion with academic supervisors, and where appropriate participants' perceptions of the researcher and her position were also explored.

The second author is an experienced clinician and senior medical educator at the medical school of a different university from that attended by the student participants in this study, and was named on the Participant Information and Consent Forms provided to participants. Although he was not directly involved in the data collection or analysis, he was the only clinician and medical educator on the supervisory panel for the project, when the researcher was a doctoral candidate. His intimate knowledge of medical schools allowed him to offer an insider's perspective on the practices being described in students' stories. As a medical educator who was at that time unfamiliar with narrative research, he was able to take a position that required the researcher to articulate with greater clarity the methods and findings of the project to diverse audiences. We believe it is very unlikely that participants' contributions would have been influenced by his involvement, because he worked at another university, they did not meet him, pseudonyms were used in material presented to him, and he was not at that time a medical school head.

Approval for the study was gained from the Human Research Ethics Committee of the teaching hospital where the fieldwork was undertaken, as well as those of the relevant Universities. The researcher took care during the fieldwork to minimise the potential for harm arising from the conduct of the research. This involved building a trusting relationship with each participant, responding sensitively to indicators of discomfort 
with her presence or questioning, and withdrawing if anyone seemed likely to be adversely affected.

\section{Setting}

The field site was a tertiary referral hospital in a major Australian city, the main location for one of several Clinical Schools of a nearby University medical school. It was situated in an outer suburb and served a linguistically and culturally diverse population with a low average socio-economic status. Staff and students also came from a wide variety of cultural backgrounds. The researcher spent two to three days per week at the hospital over a nine-month period in 2010. In order to facilitate the maintenance of her researcher identity whilst in the field, she deliberately chose a field site where she had never worked as a clinician or clinical teacher.

\section{Participants}

Student participants were enrolled in the third year of a five-year undergraduate medical degree, which was the first year of their immersion in the hospital environment. Twenty students were recruited and fifteen interviewed, from the total class of 80 third-years attending that Clinical school. All third-year students at this site and their clinical teachers were invited to participate by email and during a presentation to the group in the introductory week. Most students, including those whose stories appear here, had entered the medical school directly after completing their secondary schooling. Student sampling was mainly by convenience, with some additional snowball sampling (Liamputtong \& Ezzy, 2005b). Some students approached the researcher to enrol after hearing a presentation to the group about the 
project, seeing a flyer or hearing about the project from friends. Others were directly approached by the researcher and asked whether they would consider participating.

Seven clinical teachers were interviewed, having been recruited either in response to an email invitation circulated by the Clinical School, or by direct approach from the researcher to tutors involved in teaching events attended by the researcher with students previously recruited. Ten patients were interviewed, having been recruited by direct approach to those who had been seen during clinical teaching events, or those recommended by students as potentially suitable for interview. Results from patient and teacher interviews will be reported elsewhere.

\section{Data collection}

Data comprised participant observations, interviews and textual materials. Approximately fifty hours of participant observations of learning encounters were recorded, and the researcher also engaged in numerous informal, unrecorded conversations and observations. She accompanied students to inpatient ward rounds, bedside teaching encounters and outpatient clinics. Prior to each event it was necessary to negotiate the researcher's attendance with involved participants. These interactions were recorded using hand written field notes, which were later transcribed into documents comprising the researcher's descriptions of events, along with her interpretations and reflections on how they related to other data (Liamputtong \& Ezzy, 2005a; Murchison, 2010). Important moments identified during initial analysis of the observational material influenced the content and focus of subsequent interviews (Murchison, 2010). These moments often involved incoherence or conflict between the 
ways students had been taught to interact with patients, and how they observed others to interact with them.

Forty-seven in-depth, semi-structured interviews were carried out, audio-recorded and transcribed verbatim, including the researcher's contributions. Fifteen students were interviewed twice, once in each semester; ten patients and seven clinical teachers were each interviewed once. Stories that allowed the exploration of taken-for-granted cultural practices often emerged when participants were asked to reflect on how the reality of their experiences compared with their expectations. Transcripts were carried out in such a way as to enable a dialogic narrative analysis, containing annotations noting changes in vocal volume, hesitations and intonation as well as significant nonverbal communication and ambient sounds. Excerpts from the data have been edited for this paper due to space considerations. Names of participants have been changed to ensure confidentiality.

Textual materials including course handbooks and lecture notes from the first week of the year, designed to orient the students to learning in their new environment, were collected and analysed to provide information about the formal curriculum for comparison with observed practices.

\section{Data Analysis}

Because narrative analysis is an intensive and time-consuming process, it is not feasible to analyse an entire body of data in this way. The initial stage of the analysis involved the researcher's immersion in the data by repeatedly listening to audio recordings and closely reading the field notes, interview transcripts and other texts 
(Liamputtong \& Ezzy, 2005a; Murchison, 2010; Reeves et al., 2013). After discussion with supervisors including the second author, narrative excerpts from the data were identified as candidates for deeper analysis. The candidate stories were selected on the grounds that they related to experiences of participants, both common and extraordinary (Murchison, 2010), that addressed the research question in a variety of ways. In some cases, a story provoked an emotional reaction, and reflections upon the researcher's reactions also formed part of the analysis. This process can be considered an example of thinking with stories (Bleakley, 2005; Frank, 2004a). The stories finally selected for inclusion were juxtaposed with each other in such a way as to reveal both differences and similarities between participants' experiences, enabling diverse perspectives to be represented. An iterative process of analysis and interpretation continued throughout the production of the ethnographic text.

The stories selected for this particular paper were chosen because each of them contained material salient to the argument about the relational nature of identity, particularly the construction of the patient as adversary. In addition, there are both similarities and differences between them, which permits the identification and juxtaposition of multiple 'voices'.

A dialogic narrative analysis proceeds by considering how a particular story was produced and performed in a particular context (Frank, 2010; Gubrium \& Holstein, 2009; Reissman, 2008). Key considerations include how a story was elicited, how narrators and their interlocutors or audiences collaborated in its production, what linkages or associations are suggested by the story, and how it was performed (Gubrium \& Holstein, 2009). 
The key finding of this research project is that both medical students and patients use stories to construct their identities in relation to one another. This is accomplished through interactive storytelling, as narrators portray story characters and events in particular ways and metaphorically 'position' themselves in relation to them (de Fina et al., 2006; Wortham, 2001). The best way for the reader to appreciate how this process of 'interactional positioning' works and its role in the relational construction of identities is by reading the following stories and the accompanying analytic highlights.

The research also identifies the dehumanising effects upon patients of certain customary practices within the hospital culture, as well as the potential benefits for patients of their participation in clinical teaching. In this paper we focus specifically on stories about how students gain access to patients for participation in care-related activities.

\section{Results}

\section{Seeking consent to participation: formal teaching and customary practice}

In their introductory lectures and handbooks, students were instructed to seek informed consent from all patients they wished to involve in their learning activities. The researcher also attended a tutorial designed to help students improve communication in challenging interactions with patients, in which a clinical teacher emphasised the need for sensitivity and respect when seeking permission to carry out examinations, especially of 'sensitive' parts of the body. However, during field observations, everyday practices were often observed to deviate from these instructions. For 
example, during ward rounds, when students accompanied doctors and the rest of the team from bed to bed to observe the review of patients' progress, permission for their presence was rarely sought and they were not usually introduced as students. In outpatient clinics, the researcher observed that patients' agreement to students' presence was usually sought, but often in a cursory way.

When students had the opportunity to carry out a procedure such as taking a sample of blood for testing, they were usually supervised by a doctor or nurse who would seek the patient's agreement, but sometimes by a more senior student or not at all. One such interaction took place during a break in a ward round the researcher was attending. The doctors had gathered in the nurses' station to check some pathology results on a computer screen. Two students were asked to take a blood sample from a seriously ill young man who had been seen during the round, who spoke little English. They approached his bed with the equipment and signaled they wanted to take his blood, without revealing that they were students and with no supervision. The patient's sister intervened to ask who they were and when they admitted they were students, she asked them to leave, saying: 'I don't trust you." The doctors' response to the students' account of this interaction was: "You'll never be able to do it when there are family members there."

As a result of these observations, the researcher invited students in subsequent interviews to reflect on how they would usually gain access to patients for participation in care-related activities. Although some said that consent was normally obtained, many students told similar stories to those reported here, which were consistent with common practices observed by the researcher. By common practices we mean that 
members of this community of practice have come to see a particular way of doing things as normal, even if it might be at odds with what they have previously been taught. As we will see, this is highlighted by each narrator's use of terms drawing attention to the customary nature of a particular practice, such as "usually" or "in most cases." Each of the two stories from the student interview data presented here is accompanied by key interpretations emerging from the narrative analysis.

\section{Grace's story: practising procedures}

The following is an extract from an interview with Grace. The researcher enquired what it was like asking patients if you could perform a procedure on them.

Grace: Mm. Consent is a bit different with procedures. A lot of the time the doctor will just quickly ask - it's usually a one sentence thing - "So you need to get a drip put in; is it okay if the student does it?" And then usually the patient says, "Yes" or in some cases "No." I don't think I've had any patients who have said "No" to me. But it's not unheard of, particularly if the patient has had prior experiences - which you completely understand. That being said, I do remember my venepuncture for this one man, which I don't think ended up very pleasantly for him. I caused him a lot of pain, which was unfortunate.

Researcher: Did you need to have more than one go, or - ? 
Grace: Well, my rule is that I don't have a second go on a patient. I'm not going to try twice. If I've caused - if I've failed the first time I'll let someone who's actually had experience do it.

Grace went on to describe another episode in which the patient did not feel any pain, but there was excessive bleeding, which caused Grace some distress. The researcher asked whether someone had been supervising on that occasion.

Grace: Oh yes, definitely. I wouldn't do it without supervision. I have been asked to do it without supervision in the past. But I've chosen not to. I don't have that much confidence in my skills.

Researcher: And do you think that the patient knows they could say "No"?

Grace: I think with procedures - it's a bit easier for the patient to understand why we need to practice just because - it's a procedural skill and you can't quite learn it out of a textbook. And I think that's how we approach it as well. Procedural skills just have to be done ... and so - we - feel - less guilty - with um - um - not - a hundred per cent consenting the patient as we should, and as we've been taught in the past - of you know, who we are, why we're doing it and things like that. We're happy to just do it on a patient even though they're not quite aware if we're a student or if we're practising.

Researcher: And do you get an impression that doctors ... think patients should let students do procedures on them? 
Grace: I think doctors are more on the side of the students when it comes to these things, just because they've been students in the past and they've gone through the same thing. ... In most cases they'll try to push for - not push, but they'll just ask on behalf of you and often because they're the doctor, then the patient will agree. And that's not to say that the doctor isn't aware of the patient's, maybe, misgivings. I think we're all aware, on some level, that the patient might not be a hundred per cent happy that we're doing this. But we do it anyway for the reasons that I've given, particularly for procedural skills.

As she tells this story about her personal experience of practising procedures, Grace constructs an identity for herself as a person who takes patients' interests into account, describing how she has resisted requests to undertake procedures without supervision and will not try again after an unsuccessful attempt. Her emphasis on the words $I$ and my implies that she is more concerned about patients' welfare than some other students. The use of the singular pronoun conveys to the audience that she considers herself personally accountable for her actions.

Grace describes various tactics commonly used by doctors to secure students' participation in patient care activities, including asking briefly without offering other options (is it $O K$ if the student does it?), failing to fully disclose the student's status (who we are, why we're doing it), potentially using subtle degrees of coercion (they'll try to push for-not push, but they'll just ask on behalf of you) and proceeding even when patients appear reluctant (we do it anyway). 
In contrast to her earlier use of the singular pronoun, she switches to the plural pronoun we when she defends practices that could be seen as ethically dubious. This tends to convey a diminished degree of personal responsibility by implying that her actions conform to the expectations of her supervisors and peers. In addition, she frequently hedges or qualifies her statements (I think, one hundred per cent, not quite aware, maybe), which can be used as a strategy to deflect potential criticism of her stance. There is a dramatic moment in her narrative performance when she explains how she feels about the practices she is describing (so - we - feel - less guilty - with - um - um not - a hundred per cent consenting the patient as we should). Her apparent difficulty in getting her words out conveys a sense of ambivalence about the practices she is describing.

The common expression 'consenting the patient' represents the patient as the passive object of another's actions rather than an active subject who can give or withhold consent. This way of talking and thinking about consent can diminish the patient's potential to influence the outcome, enhancing that of the doctor or student doing the 'consenting.'

When she says doctors are more on the side of the students this can be understood as a metaphor for learning as a contest in which students and doctors are on the same side, and patients are seen as competitors or adversaries. Substituting the more neutral word ask for the word push (to describe doctors' requests) enables Grace to avoid the inference being drawn that their behaviour is coercive; this has the effect of positioning her closer to them. When she refers to students' and doctors' shared history, this could 
be interpreted as an allusion to the researcher's background - implying that she would be aware of customary practices and likely to condone them.

\section{Natalie's story: attending ward rounds}

Natalie told the following story in response to the researcher asking if she could recall an encounter when a patient had said "No" to students seeing them.

Natalie: I did have another experience where a patient said no, and it was amazingly on a ward round; and we've never been asked to leave a ward round before, especially not by a patient. And we just saw this patient and it was quite an assertive registrar that was leading the ward round. And he wasn't asking any personal questions; we didn't quite understand the reason for her behaviour. And she was almost ready to be discharged, a lower level of nursing, - and she just went, you know, “Who are all these people? I don't want them here," (loudly) and he was saying "They're part of my team" (calmly) and she ended up demanding that we leave, and so we left but - but it was really nice that he was sort of advocating for us that we stay, and that it is a teaching hospital and - yeah, that was - hard to understand where that was coming from.

Researcher: When you say, 'it's a teaching hospital', do you think that they should be required to have students there?

Natalie: I was under the impression that - (pause) sorry, I know - ward rounds were actually created historically, I think, for teaching purposes, was my 
understanding. That - not only is it the most efficient way to review every patient, but that the consultant would teach the registrar, the registrar would teach the intern - and I don't know, I'd never seen a patient exercise the right before, to demand that we leave. Yeah, and we were all pretty disappointed at that.

Researcher: Did you feel that was an unreasonable thing?

Natalie: I did. For a ward round - I can understand if it was a procedure, or - a really personal thing - we've been asked by the doctors to leave ward rounds before if they were seeing a palliative patient; or breaking news about cancer to a patient's family or that type of thing. But we'd never been asked to leave a ward round by a patient - and most doctors would never give patients the option; and don't introduce us as students.

Researcher: So does that mean doctors think patients ought to be seeing students, or having them present?

Natalie: I think so, yeah. And I think they probably realise that it's not helpful to be giving patients the option not to see students. I think they realise that if you always gave patients the option, that the students probably would miss out on a lot more than they already do. 
Natalie relates this story as an example of a patient saying "No." Setting the scene, she explains that she is about to tell a story about an extraordinary event in her experience: a patient saying no on a ward round. She conveys her evaluation of the patient and the doctor by choosing certain verbs to portray their actions (she was demanding whereas he was advocating), but also by representing each person's speech, as if directly quoting them. When she recounts how the patient says: Who are all these people? I don't want them here," she speaks loudly and in an agitated fashion. In contrast when she represents the doctor as saying: They're part of my team, she speaks more calmly. Although the word team is probably being used here in the sense of the particular unit (as in the cardiology team) there are echoes of the metaphor of learning as a contest, which was more obvious in Grace's reference to doctors being on the side of the students.

Bakhtin called this use of language ventriloquation and observed that it is commonly employed, not only in novelistic writing, but also in everyday interactions. In other words, narrators ventriloquate or "speak through" the words of story characters to indirectly express their evaluations of people or events (Bakhtin, 1981; Reissman, 2008; Wortham, 2001). This can be considered as a rhetorical device, which narrators use to persuade their audience to evaluate characters as they themselves do.

Natalie relates her account of a specific interaction to what she has observed to be usual practice. She refers to the deep cultural roots of the practice of using ward rounds as occasions for teaching and learning to support her position that the actions of the doctor and students in the story were consistent with cultural norms. Natalie does further rhetorical work when she asserts that if doctors gave patients the option not to 
see students they would miss out more than they already do - implying that students have difficulty gaining sufficient exposure to patient care activities, even under the current conditions of gaining access. She also claims that the nature of this particular interaction did not justify excluding students, giving examples of situations in which this would be the case.

In the subsequent discussion, we consider what these findings contribute to knowledge about the nature of identity construction in the context of medical education. We also consider the relationships between the identities of students, patients and doctors that emerge when medical students talk about their participation in patient care activities, and some implications for clinical education and practice.

\section{Discussion}

\section{Identities emerge in a social and cultural context}

As mentioned in the Introduction, identities emerge in social and cultural contexts, which can be understood as communities of practice (Lave \& Wenger, 1991; Wenger, 1998). In the teaching hospital, medical students become familiar with commonly held values and accepted interpretations of events, which influence how members of that community treat each other. Practices also arise in social and historical contexts, which influence the meanings people attach to them. When Natalie talks about doctors withholding information from patients about students' presence at ward rounds, she explains that it is a long established tradition for ward rounds to be used as occasions for teaching. Grace also refers to the fact that doctors have gone through the same 
thing as the students, which she argues renders them natural allies in students' quest for clinical experience.

The stories told by Grace and Natalie contain accounts of specific incidents, but they also relate these events to the customary practices they have observed doctors to follow to secure students' participation. When asked to reflect on these practices, their responses differ. Natalie engages in considerable rhetorical work, attempting to persuade her audience that the customary way of gaining access to hospital patients has a long history, and that it is justified because informed patients would be likely to decline and prevent students from gaining sufficient clinical exposure. Grace's response is more complex: she conveys a sense of ambivalence about the practices she is defending. This is most notable when she becomes extremely hesitant as she describes how she and her peers feel about disregarding proper consent processes in the context of practising minor procedures. However, she continues to assert that the practices she has observed are justified in the interest of students getting the practice they need.

The identity work of these stories can be understood as multilayered and multi-sited; in other words it takes place in multiple contexts. Although these stories tell about students' interactions with patients, they were told during research interviews. The identity of this researcher - known by participants to be a doctor herself - has to be taken into account in the analysis. For example, when Grace says: "I think we're all aware ..." there is an implication that she is including the interviewer in this "we". The students' knowledge of her profession and familiarity with the hospital world may have influenced their openness about dubious consent practices. 
Many authors have demonstrated how the biomedical perspective can be afforded almost exclusive legitimacy in medical discourse, at the expense of patients' expressions of their subjective experience (Anspach, 1998; Lingard et al, 2003). This can be characterised as a monologic way of relating to patients, which limits their potential for active and collaborative participation in educational activities or their own health care (Bleakley et al., 2011). Natalie's amazement at a patient voicing her objections to students' presence indicates that she expects patients to be passive and compliant in this context. Her depiction of a typical ward round interaction is monologic: the doctor sets the agenda without reference to the patient, the presence of students is not disclosed, and no choice offered as to whether students will be present.

\section{Constructing the patient as adversary}

In both Grace's and Natalie's stories, patients are positioned as adversaries who would thwart students' learning needs if they were fully informed and given options, whereas doctors are characterised as being students' champions and allies. The narrators' selfidentification with the doctors is accomplished by their use of direct statements, such as when Natalie says the doctor was advocating for them, or when Grace says doctors ask on behalf of you. It is also conveyed indirectly, for example when Grace downplays the suggestion of coercion, which might be inferred from her use of the word push, by substituting the words just ask, or when Natalie conveys her positive evaluation of doctors' actions by offering arguments to justify them. 
Using the expression on the side of the students can be interpreted as a metaphor that characterises learning as a contest, with students and doctors on one side and patients on the other. In a study exploring how people conceptualise doctor-patient relationships, most participants chose metaphors that highlighted their adversarial nature (Rees et al, 2007). Grace's and Natalie's positioning of patients as adversaries in relation to students suggests that their emerging professional identities incorporate this construct of professional-patient relations. Natalie implies that in order to be considered reasonable, patients should be passive and compliant with doctors' requests. Although Grace says that she can understand why patients might say "no" when asked if a student can take a blood sample, her advocacy of commonly employed deceptive practices is at odds with this view.

\section{Identity construction as a creative struggle}

Although the norms and customary practices which students observe are influential, each individual brings his or her existing values and experience to their interpretation of those around them and their actions. My findings support the view that students are "active subjects who make choices, resist subjugation, accommodate power differentials and ... actively craft themselves internally" during their training (Holmes et al., 2011, p. 109).

Grace's depiction of herself in this interaction appears to include two 'voices' or identities. At the beginning of the story, she represents herself as a person who resists others' expectations in order to uphold high ethical standards. She emphasises how she places patient comfort above her own learning needs, for example by declining to 
comply with requests to perform a procedure unsupervised. However, later she indicates that she is willing to compromise her standards in relation to consent in order to conform to cultural expectations. Her personal responsibility for the first position is underlined by her emphatic use of the singular pronouns $I$ and $m y$, which implies that some other students place less value on patient interest than she does. In contrast, when she offers arguments to justify proceeding even if patients are reluctant or poorly informed, Grace shifts her pronoun use to the plural. Using we in this context highlights how her actions are in line with those of her peers, diminishing her individual responsibility; this appears to be in conflict with her earlier position.

In a previous study, students' narratives about how they had acted when they were asked to perform or witness examination without valid consent showed that they tended to construct their accounts in such a way as to represent themselves in a positive light (Rees \& Monrouxe, 2011). Like Grace, they emphasised their personal accountability if they had refused to accede to a doctor's request but when relating how they had complied despite misgivings, they highlighted their sense of powerlessness. When Grace begins to explain how she feels about the practices used to enable students to practice on patients, her performance becomes very hesitant. Her words offer support for customary practices but her mode of delivery of those words conveys a different message, conveying a sense of ambivalence and struggle between her emerging and more established identities.

Unlike Grace, Natalie does not display ambivalence towards the practices she is describing; instead she presents a series of arguments in justification. The means by which she constructs the identities of the patient, teacher and herself relies heavily on 
the technique of interactional positioning. In other words, she depicts the patient and doctor and students in particular ways and in doing so, positions herself in relation to them, indirectly constructing an identity for herself. She uses the device of ventriloquation - speaking through the words of others - as well as varying her vocal tone and volume as she tells her story, which helps to depict the patient in a negative way and the doctor as her advocate. She also employs verbs to portray characters' actions that cast the patient as unreasonable and demanding, and the doctor as assertive, but fair.

\section{Implications for education and future practice}

We have shown how students' stories about their encounters with patients are occasions for identity construction and that identities are not constructed in isolation, but always in relation to others. These stories were gathered during research interviews, but clinical teachers in the course of their everyday work could facilitate such storytelling occasions with students, for example when de-briefing after a ward round or procedure. Clinicians could reflect on whether their words and actions could be interpreted by students as identifying patients as adversaries, which is likely to result in students also identifying them as such since they tend to see doctors as their advocates and allies. They could also consider whether withholding information material to a patient's decision constitutes a misuse of the power inherent in their position. Students' unease, for example the ambivalence displayed by Grace, could be a trigger for educators to examine possible ethical issues in relation to the practices being described. 
Socio-cultural theories of learning have established that the power dynamics of learning encounters are highly influential to identity construction (Bleakley et al., 2011; Rees et al., 2013; Wenger, 1998; Wortham, 2006). Thinking about power is relevant to the analysis of common practices, especially those that limit patients' opportunities to make choices about their involvement in clinical teaching or to take on active roles (Donetto, 2012). However, it is important to acknowledge power as a dynamic property of social systems and organisational structures, whose roles, rules and customary practices present both constraints and opportunities to individuals' capacity to uphold moral values (Donetto, 2012). If this is not recognised, unreasonable expectations may be placed on individuals to effect change, without attending to the social structures within which they operate (Donetto, 2012).

Since clinical teaching and learning take place at the intersection of health care and medical education, students' emerging identities are influenced by the way all doctors interact with patients - not only those who have a formalised teaching role. For this reason, knowledge about identity construction needs to extend beyond those who consider themselves to be educators, to include all clinicians who come in contact with students in their everyday work.

\section{Strengths and limitations of the study}

The specific practices referred to in this study would be expected to vary between medical schools with different contexts; for example, rural or community based schools or those with higher proportion of mature aged students and recent school 
leavers. However, it is likely that the customary practices of clinical teaching and power dynamics in any particular context will influence the identities constructed by students, in relation to those with whom they interact, in that context. It would be useful to carry out similar studies in a variety of clinical settings including ambulatory and primary care settings.

In the medical school that was the focus of this study, third-year students rotated to a different ward or clinical unit every 4 weeks, and they would often meet each patient on only one or two occasions. It is important to recognise that medical and other health professional students are sometimes involved in patient care over extended periods and may therefore be in a position to form trusting relationships and contribute to care in meaningful ways (Manninen et al, 2014). Indeed, at the same medical school the final year students performed such a role and were known as student interns; they were not part of this study, but it would be valuable to investigate students' identity work during this later phase of their training.

Because the data consisted mainly of oral communication converted to text, there was limited scope to consider the non-verbal dimensions of identity construction. This has been addressed by some other researchers through the use of video-recordings of learning activities in the clinical space (Rees et al., 2013). Similarly, the present study did not examine how identities might change over time, focusing instead on how they are constructed in-the-moment. Some other researchers have gathered more longitudinal data using solicited audio diaries, which students complete over a period of time (Dornan et al., 2015; Monrouxe, 2009b). 
The researcher's dual identities as ethnographer and physician undertaking fieldwork in a hospital can be seen as both a limitation and a strength. A medical background could make it difficult to appreciate how strange or troubling certain practices might be to those unfamiliar with the setting. The stories told by participants and their actions during observed events might have been influenced by their assumptions about the researcher's attitudes, based on her professional background. However, her access to clinical encounters, which provided opportunities to collect rich data, appeared to be facilitated by the fact that she was a doctor.

\section{Conclusion}

It is well established in the field of education that identity formation is an integral part of learning, but the recognition of this in medical education circles is relatively recent. In the day-to-day work of clinical teaching and learning there is great scope to increase awareness of the identity work that takes place within every encounter, and also when people talk about their experiences. This paper adds to the existing medical education literature because it highlights the relational nature of identity construction during interactive storytelling. New insights have been produced by incorporating dialogic narrative analysis into an interpretive ethnographic project to investigate the meanings generated when stories are told about learning in clinical environments.

In these stories, the students characterise their teachers as allies who help them to gain access to patients. It is expected that students come to identify more with doctors than patients as they progress in their medical education. However, we have shown here 
how some common practices can identify patients as adversaries in relation to doctors, and how students can also adopt such a position when they align their identities with those of the doctors. This has potential implications for students' future practice because it helps to shape their emerging professional identities. Students observe how doctors use their powerful position to exert pressure or withhold information in order to advance their own interests or those of their students. This could affect their future practice, for example which possible diagnoses or treatment options they choose to reveal, or the reasons they give for making a particular recommendation. They may also fail to recognise the power imbalance inherent in doctor-patient relationships and how this might complicate the process of obtaining informed consent or create barriers to patients expressing their concerns. The potential links between students' observations of customary practices, emerging identities and future practice could be a worthwhile area for future research.

In view of these findings, we argue that clinical teachers need to develop an understanding of how their own identities, as well as those of students and patients, are relationally constructed in everyday clinical encounters and subsequent conversations. This should facilitate a move towards more collaborative, rather than adversarial, ways of achieving medical students' participation in patient care-related activities.

\section{Acknowledgements}

This project received funding support from the Australian Government Department of Education and Training by way of an Australian Postgraduate Award to the first author. The authors gratefully acknowledge the generosity of study participants, and the support and guidance from supervisors Marilys Guillemin, Geoffrey McColl, and 
Richard Chenhall and advisors Robyn Woodward-Kron, Celia Thompson, Michelle Leech and Lyn Gillam.

\section{References}

Anspach, R. R. (1998). Notes on the sociology of medical discourse: the language of the case presentation. Journal of Health and Social Behaviour, 29(4), 357375.

Bakhtin, M. (1981). Discourse in the Novel (C. Emerson \& M. Holquist, Trans.). In M. Holquist (Ed.), The Dialogic Imagination (pp. 59-422). Austin, Texas: University of Texas Press.

Becker, H. S., Geer, B., Hughes, E., \& Strauss, A. L. (1961). Boys in White: Student culture in medical school. Chicago: The University of Chicago Press.

Bleakley, A. (2005). Stories as data, data as stories: making sense of narrative inquiry in clinical education. Medical Education, 39(5), 534-540.

Bleakley, A., Bligh, J., \& Browne, J. (2011). Medical Education for the Future (2001 Ed. Vol. 1). Dordecht: Springer.

Chretien, K., Goldman, E., Craven, K., \& Faselis, C. (2010). A qualitative study of the meaning of physical examination teaching for patients. Journal of Geberal Internal Medicine, 25(8), 786-791.

Cohen, M. J. M., Kay, A., Youachim, J. M., \& Balacius, J. M. (2009). Identity transformation in medical students. The American Journal of Psychoanalysis, 69, 43-52.

Coldicott, Y., Pope, C., \& Roberts, C. (2003). The ethics of inimate examination. British Medical Journal, 326, 97-101.

Cooke, M., Irby, D., \& O'Brien, B. (2010). Educating Physicians: A call for reform of medical school and residency. Stanford, CA: Jossey-Bass.

Cruess, R. L., Cruess, S. R., Boudreau, D. J., Snell, L., \& Steinert, Y. (2014). Reframing Medical Education to Support Professional Identity Formation. Academic Medicine, 89, 1446-1451.

de Fina, A., Schiffrin, D., \& Bamberg, M. (Eds.). (2006). Discourse and Identity. Cambridge: Cambridge University Press.

DelVecchio Good, M.-J. (2011). The Inner Life of Medicine: A Commentary on Anthropologies of Clinical Training in the Twenty-first Century. Culture, Medicine and Psychiatry, 35, 321-327.

Denzin, N. (1997). Interpretive ethnography: Ethnographic practices for the 21st centiry. Thousand Oaks: Sage.

Donetto, S. (2012). Talking about power in medical education. Medical Education, 46, 1141-1151.

Dornan, T., Pearson, E., Carson, P., Helmich, E., \& Bundy, C. (2015). Emotions and identity in the figured world of becoming a doctor. Medical Education, 49, 174-185.

Dyrbye, L., Thomas, M., \& Shanafelt, T. (2005). Medical Student Distress: Causes, Consequences and Proposed Solutions. Mayo Clinic Proceedings, 80(12), 1613-1622. 
Fletcher, K., Furney, S., \& Stern, D. (2007). Patients Speak: What's really important about bedside interactions with physician teams. Teaching and Learning in Medicine, 19(2), 120-127.

Fletcher, K., Rankey, D., \& Stern, D. (2005). Bedside interactions from the other side of the bedrail. Journal of General Internal Medicine, 20, 58-61.

Frank, A. W. (2004a). Asking the right question about pain: narrative and phronesis. Literature and Medicine, 23(2), 209-225.

Frank, A. W. (2004b). The renewal of generosity: Illness, medicine and how to live. Chicago: The University of Chicago Press.

Frank, A. W. (2010). Letting stories breathe: a socio-narratology. Chicago and London: University of Chicago Press.

Gardiner, M., \& Bell, M. M. (1998). Bakhtin and the Human Sciences: A brief introduction. In M. M. Bell \& M. Gardiner (Eds.), Bakhtin and the human sciences (pp. 1-12). London: Sage.

Garro, L. C., \& Mattingly, C. (2000). Narrative as construct and construction. In C. Mattingly \& L. C. Garro (Eds.), Narrative and the cultural construction of illness and healing (pp. 1-49). Berkeley: University of California Press.

Goldie, J. (2012). The formation of professional identity in medical students: Considerations for educators. Medical Teacher, 34, e641 - e648.

Good, B. J., \& Good, M.-J. D. (2000). "Fiction" and "Historicity" in doctors' stories:

Social and narrative dimensions of learning medicine. In C. Mattingly \& L. C. Garro

(Eds.), Narrative and the cultural construction of illness and healing (pp. 50-69).

Berkely: University of California Press.

Gubrium, J. F., \& Holstein, J. A. (2009). Analyzing narrative reality. Los Angeles: Sage.

Holmes, S., Jenks, A., \& Stonington, S. (2011). Clinical Subjectivation: Anthropologies of Contemporary Biomedical Training. Culture, Medicine and Psychiatry, 35, 105-112.

Holquist, M. (2002). Dialogism (Second ed.). London and New York: Routledge.

Iedema, R., \& Caldas-Coulthard, C. R. (2008). Introduction. In R. Iedema \& C. R. Caldas-Coulthard (Eds.), Identity Trouble (pp. 1-14). Houndmills: Palgrave Macmillan

Korica, M., \& Molloy, E. (2010). Making sense of professional identities: Stories of medical professionals and new technologies. Human Relations, 63(12), 1879-1901.

Lauckner, H., Doucet, S., \& Wells, S. (2012). Patients as educators: the challenges and benefits of sharing experiences with students. Medical Education, 46(10), 992-1000.

Lemke, J. L. (2008). Identity, development and desire: Critical questions. In C. R. Caldas-Coulthard \& R. Iedema (Eds.), Identity Trouble: Critical Discourse and Contested identities (pp. 17-42). Basingstoke and New York: Palgrave Macmillan.

Liamputtong, P., \& Ezzy, D. (2005a). Ethnography Qualitative research methods (2 ed., pp. 160-180): Oxford University Press.

Liamputtong, P., \& Ezzy, D. (2005b). Qualitative Research methods (2nd ed.). Melbourne: Oxford University Press.

Lief, H., \& Fox, R. (1963). Training for "Detached Concern" in medical students. In H. Lief, V. Lief, \& N. Lief (Eds.), The Psychological basis of medical practice. New York: Harper and Row. 
Lingard, L., Garwood, K., Schryer, C. F., \& Spafford, M. M. (2003). A certain art of uncertainty: case presentation and the development of professional identity. Social Science and Medicine, 56, 603-616.

Loftus, S. (2012). Rethinking clinical reasoning: time for a dialogical turn. Medical Education, 46, 1174-1178.

Manninen, K., Henriksson, E. W., Scheja, M., \& Silén, C. (2014). Patients' approaches to students' learning at a clinical education ward-an ethnographic study. BMC Medical Education, 14. Retrieved from http://www.biomedcentral.com/1472-6920/14/131

McLachlan, E., King, N., Wenger, E., \& Dornan, T. (2012). Phenomenological analysis of patient experiences of medical student teaching encounters. Medical Education, 46(10), 963-973.

Monrouxe, L. (2009a). Identity, identification and medical education: why should we care? Medical Education, 44(1), 40-49.

Monrouxe, L. (2009b). Solicited audio diaries in longitudinal narrative research: a view from inside. Qualitative Research, 9, 81-103.

Monrouxe, L., Rees, C., \& Bradley, P. (2009). The Construction of Patients' Involvement in Hospital Bedside Teaching Encounters. Qualitative Health Research, 19(7), 918-930.

Murchison, J. M. (2010). Ethnography Essentials. San Francisco: Jossey-Bass.

Nair, B. R., Coughlan, J. L., \& Hensley, M. J. (1997). Student and Patient perspectives on bedside teaching. Medical Education, 31, 341-346.

Rees, C., Ajjawi, R., \& Monrouxe, L. V. (2013). The construction of power in family medicine bedside teaching: a video observation study. Medical Education, 47(2), 154-165.

Rees, C., Knight, L., \& Wilkinson, C. (2007). Doctors being up there and we being down there: A metaphorical analysis of talk about student / doctor relationships. Social Science and Medicine, 65, 725-737.

Rees, C., \& Monrouxe, L. V. (2008). 'Is it alright if I-um-we unbutton your pyjama top now?' Pronominal use in bedside teaching encounters. Communication and Medicine, 5(2), 171-182.

Rees, C., \& Monrouxe, L. V. (2011). Medical students learning intimate examinations without valid consent: a multicentre study. Medical Education, 45(3), 261-272.

Reeves, S., Peller, J., Goldman, J., \& Kitto, S. (2013). Ethnography in qualitative educational research: AMEE Guide No. 80. Medical Teacher, 35, e1365e1379.

Reissman, C. K. (2008). Narrative Methods for the Human Sciences. Los Angeles, Ca: Sage Publications.

Rice, T. (2008). "Beautiful murmurs": stethoscopic listening and acoustic objectification. The Senses and Society, 3, 293-306.

Romano, J. (1941). Patients' attitudes and behavior in ward round teaching JAMA (Chicago, Ill.), 117( 9), 664-667.

Sinclair, S. (1997). Making Doctors: An institutional apprenticeship. Oxford \& New York: Berg.

Wenger, E. (1998). Communities of Practice: Learning, Meaning and Identity. Cambridge: Cambridge University Press. 
Wilson, I., Cowin, L. S., Johnson, M., \& Young, H. (2013). Professional Identity in Medical Students: Pedagogical Challenges to Medical Education. Teaching and Learning in Medicine, 25(4), 369-373.

Wortham, S. (2000). Interactional Positioning and Narrative Self-construction. Narrative Inquiry, 10(1), 157-184.

Wortham, S. (2001). Narratives in Action: A Strategy for Research and Analysis. New York, NY: Teachers College Press.

Wortham, S. (2006). Learning Identity: The joint emergence of social identification and academic learning. New York: Cambridge University Press. 